\title{
The agreement between venous and arterial blood gases in critical care and ward patients: is there a need to stratify for shock?
}

\author{
Matthew L. Wong, MD, MPH · Joshua W. Joseph, MD, MS
}

Received: 9 January 2018/Revised: 10 January 2018/ Accepted: 10 January 2018/Published online: 5 February 2018

(c) Canadian Anesthesiologists' Society 2018

\section{To the Editor,}

We read Martin and Priestap's paper addressing the agreement between venous and arterial blood gases in both critical care and ward patients with great interest. ${ }^{1}$ The topic is relevant to all clinicians who care for the critically ill. It clearly shows that there is a strong correlation between arterial and venous gas analysis results when considered in aggregate. Nevertheless, I think that their report could be strengthened if it employed a stratified analysis. That is, the relationship between arterial and venous laboratory values may not be uniform across patients with differing severities of illness. While arterial and venous blood gases may be nearly identical in patients with adequate perfusion, the differences may be exaggerated in patients with shock. For example, this could be determined by examining the bias and standard deviation of the differences in blood gas values for patients with mean lactate values $>4 \mathrm{mEq} \cdot \mathrm{L}^{-1}$ or with a mean $\mathrm{pH}<7.25$, which we encourage authors to report.

Conflicts of interest None declared.

Editorial responsibility This submission was handled by Dr. Hilary P. Grocott, Editor-in-Chief, Canadian Journal of Anesthesia.

\section{Reference}

1. Martin CM, Priestap F. Agreement between venous and arterial blood gas analysis of acid-base status in critical care and ward patients: a retrospective cohort study. Can J Anesth 2017; 64: 1138-43.

This letter is accompanied by a reply. Please see Can J Anesth 2018; 65: this issue.

Matthew L. Wong and Joshua W. Joseph contributed to the manuscript equally in all forms.

M. L. Wong, MD, MPH $(\bowtie) \cdot$ J. W. Joseph, MD, MS

Department of Emergency Medicine, Beth Israel Deaconess

Medical Center, Boston, MA, USA

e-mail: MLWong@bidmc.harvard.edu 